\title{
Rehabilitation by Amputation
}

\author{
KEITH FLESHMAN, PETER HILL AND ERNEST FRITSCHI \\ All Africa Leprosy and Rehabilitation Training Centre, \\ Addis Ababa, Ethiopia
}

\begin{abstract}
A retrospective study of lower limb amputations in leprosy patients at ALERT is reported. Charts were reviewed and patients were interviewed. Surprisingly, there was very high patient acceptance of both the amputation and of even rather mediocre prosthesis. In addition almost all patients became independent and self-supporting by a culturally acceptable means. Prior to amputation most had been totally dependent. It is therefore concluded that amputation is acceptable rehabilitative surgery for those whose feet have become so mutilated as to prevent full weight bearing.
\end{abstract}

For many years two dicta have ruled surgeons contemplating amputation; first, any leg is better than no leg; second, the longest stump is the best stump. These were "the law and the prophets", and all that remained was but commentary.

In developing countries these laws have been clung to with fervour. Where excellent prosthetic service was not available, amputation was held to be anathema. Cochrane's text (1964) does not even discuss criteria for amputation. More recently Fritschi (1971) regards amputation as the last and least desirable therapy. After all attempts at sequestrectomy, grafting, tendon transference, arthrodesis, casts, and cumbersome and ugly footwear and orthoses have failed, then with reluctance amputation is accepted. He says, "No surgeon is justified in removing a limb unless he can provide one which is an improvement".

In an attempt to evaluate these attitudes objectively a retrospective study was done. An attempt was made to find, examine, and question all amputees attending the ALERT clinics. A monthly prosthetic review clinic was established, facilitating not only the study but preventive and curative maintenance of prosthesis as well. At the beginning of the study half the patients had stump ulcers. At the penultimate clinic with 24 attending, only 2 had ulcers and one of these had a new prosthesis.

Sixty-eight cases with 81 amputations were reviewed. Fifty-eight persons with 71 amputations (12 bilateral) were interviewed. Ten persons had died or could not be traced, and only their charts were reviewed.

Fifty-seven patients were men. Eleven were women. Ten men and 3 women had bilateral amputations. There was a significant tendency for these patients to be more aggressive and harder workers than their fellows. This may account for their more frequent and chronic injuries.

The average age at time of amputation was about 35 in both men and women

*Received for publication 19 June, 1975. 
following an average period of 6 years of what the patient considered to be total disability. Six amputations were done for epithelioma of the foot. (Of these 4 died of metasteses in less than 5 years. Two are living and apparently well after 2 years.) The remaining amputations were done for combined mutilations of bone and soft tissue.

Levels of amputations were as follows:

Mid foot

Pirogoff's

Syme's

Below knee (mid-leg)

Through knee

Above knee
4

12 (6 were un-united)

18

43

2

2

In the case of both Pirogoff's and Syme's amputations there was a marked tendency for posterior displacement of the heel pad if the Achilles tendon had been left intact.

An attempt was made to map stump sensation. No meaningful pattern was found except that there was more sensation on the sides than on the end of most stumps. Therefore it can be concluded that a prosthesis distributing weight around the sides of the leg is safer than one using end bearing technique.

Almost all stump ulcers were due to ill-fitting sockets. The large majority healed after revision or replacement of the old socket. As expected there was direct correlation between the absence of sensation and persistent stump wound and vice versa.

The mobility of patients was very difficult to assess, and could only be determined approximately by asking the patient where he walked to his work and how many times per week. The average distance estimated per day was $4 \mathrm{~km}$, with a range from $200 \mathrm{~m}$ to $18 \mathrm{~km}$. All of the group except 6 were using either a pair of crutches or walking sticks for additional balance or support.

Associated hand deformities were very significant:

8 had normal hands (WHO grade 0 )

4 had areas of anesthesia (WHO grade 1)

14 had anesthesia with intrinsic paralysis (WHO grade 2)

26 had mutilated hands (WHO grade 3 )

(Unfortunately, this aspect of the problem was not considered during initiation of the study, and so only 52 of the interviewees provided the data.)

The most dramatic aspect of this study was in the area of patients' satisfaction and rehabilitation. One man who had had chronic ulcers was discontented with his amputation. One who had ulcers, but whose below knee amputations were done by a train was also discontented. Of the remaining 56, all felt that amputation had been of real benefit to them.

All except 6 were content with their prosthesis. About half of those who were content to wear simple elephant boots desired a normal-looking shoe for cosmetic reasons.

The patients' attitudes varied from stoic acceptance of amputation as a necessary phase of their treatment to frank appreciation. One man, now a landlord, with Syme's amputation for 35 years, had used an inverted cowhorn as a prosthesis for 25 years (Fig. 6). He now has a cosmetic resin and plastazote 
shoe (Fig. 7(a)). His testimony was, "When the amputation was first done, I realized that it was necessary to save my life. Nevertheless, I was very angry with the doctor, my friends and all people. Since then I see my friends who had ulcers then, still hobbling about on their ulcers. Whereas, I with the help of God and a stick, go where I wish and do what I wish."

Of all the 58 persons interviewed only 5 were not self supporting. Two of these had been inpatients in other institutions for years.

3 persons were inmates of the Government Reception Centre for vagrants.

12 persons were employed in crafts and daily labour.

12 persons were self-employed in petty trade or were property owners with houses which they were giving for rent.

25 persons were self-employed as beggars.*

Of the beggars only 1 became a beggar because of the amputation, and this was a woman who stated that she had been divorced, not because of her leprosy, but because of the amputation. All had been completely disabled for an average of 6 years with a variation from 1 month to 30 years. All save 7 had mutilated hands. Because they had to travel by bus or walking $15 \mathrm{~km}$ a day to beg it would seem that restoring the ability to walk with a prosthesis freed them from total dependence. The fact that of 25 beggars 17 had mutilated hands and 5 more had contracted claw hands would indicate that perhaps the hand deformity was more contributory to their choice of profession than was the amputation.

\section{Indications for Amputation}

(Figs 2-5)

These may be summarized as any limb which has a destruction of its weight-bearing surface and bony architecture to the extent that no reconstructive operative procedure can be performed. In the forefoot, ulceration is of ten associated with long-standing equinus deformity. It is usually possible to perform a tendon transfer, or if the foot is shortened, ankle fusion in the correct position. A good heel pad and at least half the weight bearing area of the foot is necessary for this latter procedure. A fixed ankle brace (Wollstein, 1972) is usually required (Fig. 1).

Tarsal disintegration may result in an inverted foot. This can usually be corrected by sub-talar arthrodisis, provided a stable forefoot is present, and an adequate area of scar-f ree weight-bearing plantar skin is available (Fritschi, 1971).

Tarsal disintegration can also result in a mid-tarsal disorganization with resulting rocker bottom foot. This condition is rarely amenable to reconstruction. Similarly, a heavily scarred heel, especially if this is associated with an unstable forefoot, will usually require amputation. Calcaneal disintegration with Achilles migration prevents use of the forefoot.

When in any doubt a trial should first be made with a fixed ankle brace (FAB walker) with rocker sole. If this does not maintain the foot ulcer free, then an amputation is indicated.

* We fully justify this as a self employment on several bases: It is hard labour, requiring several kilometres of travel daily. It requires initiative and perseverance. In the Orthodox Christian and Muslim communities, the giving of alms is a godly act-even a means of grace, and the receiver of alms is therefore a necessary member of society in Ethiopia. 

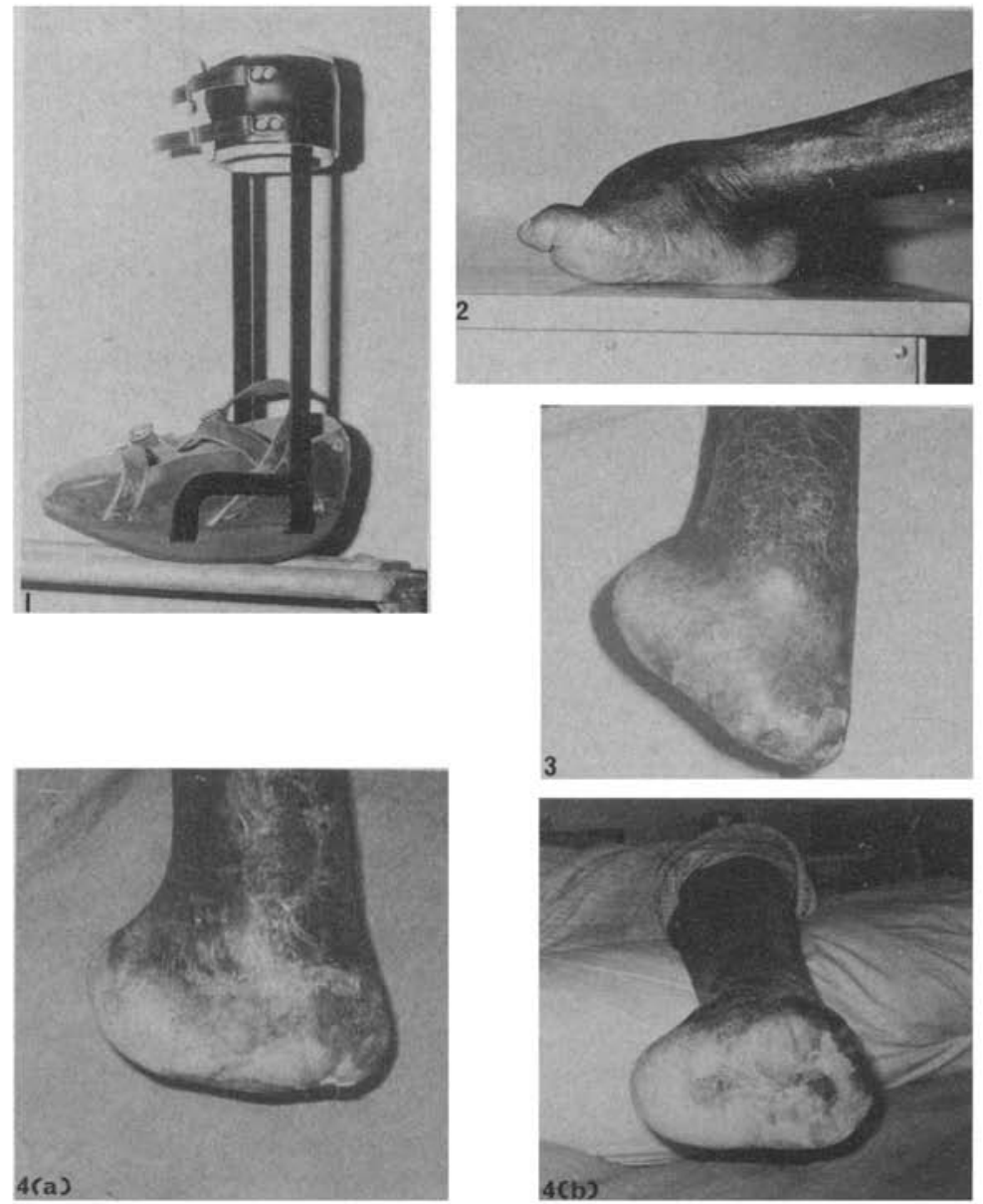

Fig. 1. The FAB walker incorporates a moulded plastazote insole on a microcellular rubber foundation with a rigid sole, a fixed ankle and a rocker bottom. This eliminates all foot and ankle flexion transmitting motion to the shoe contact surface. Force is still transmitted from the tibia through the ankle joint, and so some bony continuity is required.

Fig. 2. This foot has undergone Charcot degeneration. Skin and fat are intact. The $x$-ray demonstrates that the weight distributing arch-truss of the foot is entirely destroyed. Further weight bearing will lead inevitably to penetration of the sole by the tibia. A Syme amputation will preserve the heel pad.

Fig. 3. Although a talectomy and calcaneo-tibial compression fusion could make this foot plantigrade it would still have less than half the weight bearing skin. Add to that the severe scarring of the tip and the balance is in favour of Syme amputation.

Fig. 4. This foot is in equinus although the loss of the forefoot masks that fact. The plantar surface is almost wholly scar tissue. The heel pad has been preserved due to the equinus and can be brought around into functional position by a Syme amputation. 
Not infrequently gangrene due to infection will demand amputation. Epithelioma occurring in chronic ulcers is not rare and demands amputation to save life. It must be confirmed by biopsy as the clinical appearance can be deceptive.

Amputations through the midfoot frequently occur spontaneously due to loss of toes and metatarsal heads. A filled shoe then makes a moderately acceptable prosthesis, but foot end ulceration, especially if there is a fixed equinus deformity, may persist unless a rigid rocker sole is applied to the shoe.

The various modifications of the Pirogoff amputation, which attempts to fuse a retained portion of the calcaneus to the tibia, fail to arthrodese in many cases. They then become dislocated backwards by the active calf muscle through the intact Achilles tendon.

Only 2 types of amputation are therefore recommended: The Syme amputation, and the below knee, where the stump is about $14-17 \mathrm{~cm}$ long with a my of ascial flap to cover the tibial end.

The Syme amputation should include excision of the malleollae and the cartilage of the tibial mortice. The Achilles tendon should be excised to prevent subsequent posterior dislocation of the flap. We make a slight fish-mouth incision at the ankle joint, saw the tibia and fibula 1 or $2 \mathrm{~cm}$ above the joint, and dissect from above downward sub-periosteally. This is less traumatic to the tissues and leaves a less bulbous and more stable pad than the classical Syme (Fritschi, 1971).

There is adequate and extensive literature on below-knee amputations in standard surgical texts. The length of $14-17 \mathrm{~cm}$ is suggested because it makes prosthesis fitting and leverage much better. The myofascial flap is needed to protect the skin from the tibial end. Especially in situations where the prosthesis is not perfect, there is a tendency to end bearing which is made safer by the thicker pad.

\section{Prostheses}

(Fig. 6-10)

For Syme's amputation acceptable leather "elephant boots" (Fig. 7) can be made by a village shoemaker. The most appropriate Symes' prosthesis seems to be a moulded long socket, bearing weight not only on the end, but on the upper tibial flare, and on the patellar tendon as well. This may require a window for donning the prosthesis if the heel pad is bulbous. If facilities are adequate a rocker foot should be provided for cosmetic reasons. This is a frequent request from the patient with an "elephant boot".

For below-knee amputations a bent knee prosthesis with simple pylon can be made by a competent cabinet maker or wood carver (Fig. 8). We have not found that this leads to knee contracture. Nor does it hinder later patellar tendon bearing prosthesis fitting. It should be used in centres not having a regular limb shop.

At the next level of technical sophistication is the Pfaltzgraff prosthesis (a plastazote socket with resin leg moulded directly to the stump) requiring somewhat more skill and special materials than the bent knee prosthesis (Pfaltzgraff, 1963) (Fig. 9). It is technically within the scope of any group making special shoes and sandals for deformed feet. However, we find that without relining about every 3 months, the plastazote liner tends to flatten. The socket is thereby enlarged and becomes end bearing rather than patellar tendon bearing. 

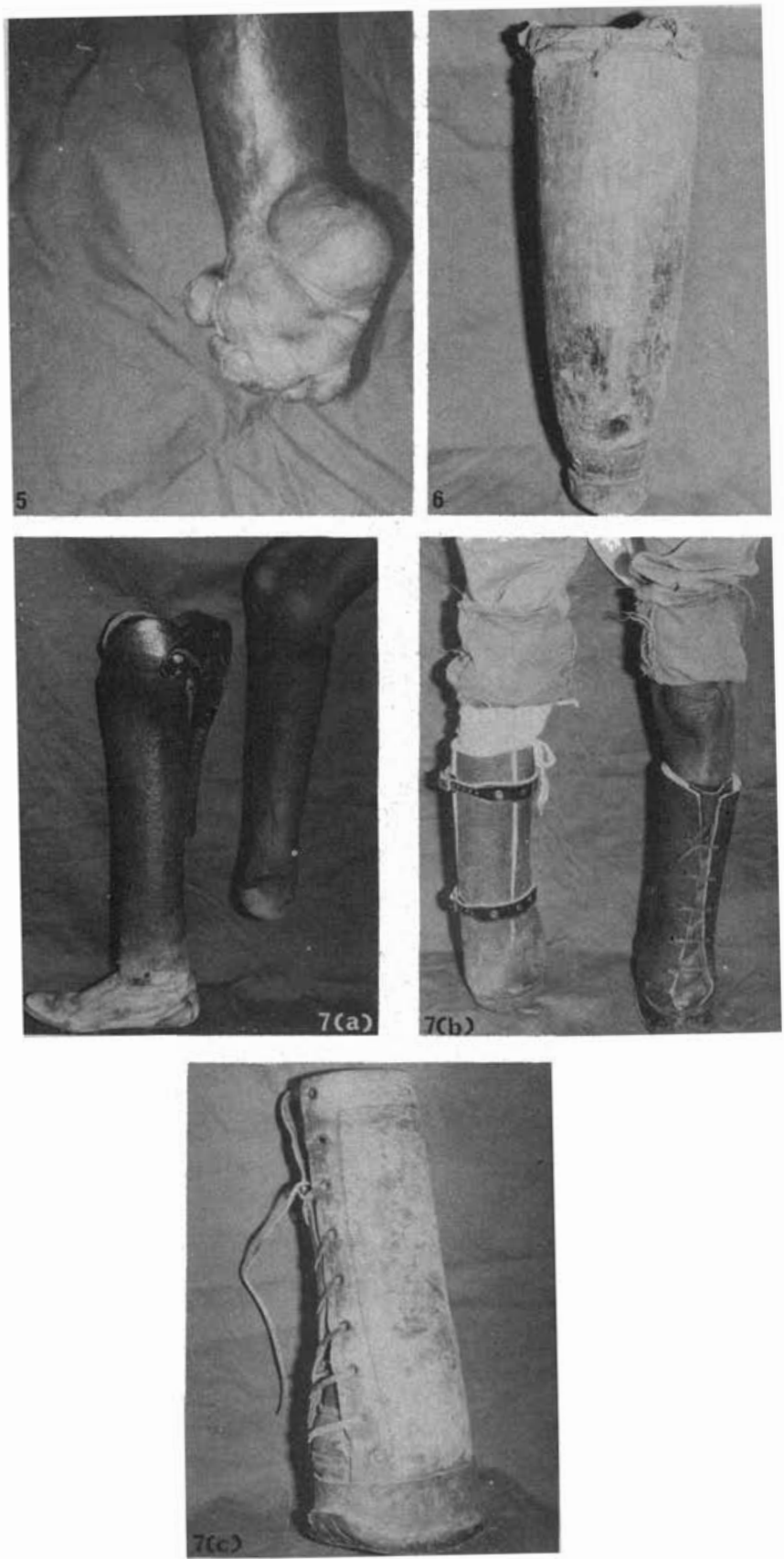
Consequently, pistoning of the stump, callosities and ham string ulcerations occur.

The hard socket patellar tendon bearing is by far the best prosthesis if it fits perfectly. It is technically difficult to make, but any skilled craftsman can learn this task, though it does require special training, tools and materials. Many leprosy treatment centres are able to produce such limbs. Others should seek opportunity to send a craftsman for this training.

In our situation, we think that the best foot is the SACH-rocker (Fig. 10). This is a solid ankle, cushioned heel with a rocker bottomed polymerized resin foot unitary with the leg. This has a slightly odd appearance, but gives a very good gait. The rubber forefoot of the usual Western SACH foot tends to break after about 6 months use and is thus too expensive for services with restricted resources.

\section{Discussion}

In the past when chronically ill patients were isolated from society because of their disease; when leprosaria consisted a series of low cost huts; when a patient's time was not a considered commodity, and when the patient could not expect re-integration into a society that rejected him; at that time spending months and even years in a futile attempt to save a doomed foot was perhaps justified.

Today, each person's time must be considered his valuable possession. Soaring hospital costs also must realistically be counted. In our series the average time of total disability was 6 years. During much of that time, the patients were hospitalized and/or consuming expensive materials such as bandages, antibiotics, plaster of paris and professional staff hours. The expenditure of such commodities is surely worthwhile if the natural foot can be restored to prolonged and useful service.

Our patients obvious contentment, their assumption of a place in their own society, and their increased mobility, encourage us to believe that amputation is not just mutilation but is indeed rehabilitation.

Fig. 5. There remains here an adequate area of well preserved plantar skin and fat. The bony architecture has been entirely scrambled due to osteo myelitis, Sequestration and Charcot phenomenon. Scarring has embarrassed blood supply and elephantiasis has made the skin about the ankle very fragile. Therefore a BK amputation is probably the wisest choice.

Fig. 6. This inverted cow's horn, padded with rags, served as a prosthesis for a Syme's amputation for 25 years.

Fig. 7. Several types of prosthesis for Syme's and Pirogoff's amputations. (a) A weight sharing prosthesis moulded to accept part of the weight on the heel pad and part on the tibial condyles and patellar tendon. This requires a distal end smaller than that obtained with the classical Syme's retention of moleolae (see text). (b) A resin and stockinette "Elephant Boot" with plastazote liner and window for donning. This fits a Pirogoff's amputation stump with its large distal end. (c) A simple leather and auto tyre "Elephant Boot" which can effectively have a plastazote liner. All of the above models have microcellular rubber pads for the weight-bearing stump end. Patients such as farmers who walk on very uneven surfaces prefer the elephant boot to the prosthesis with a foot. 

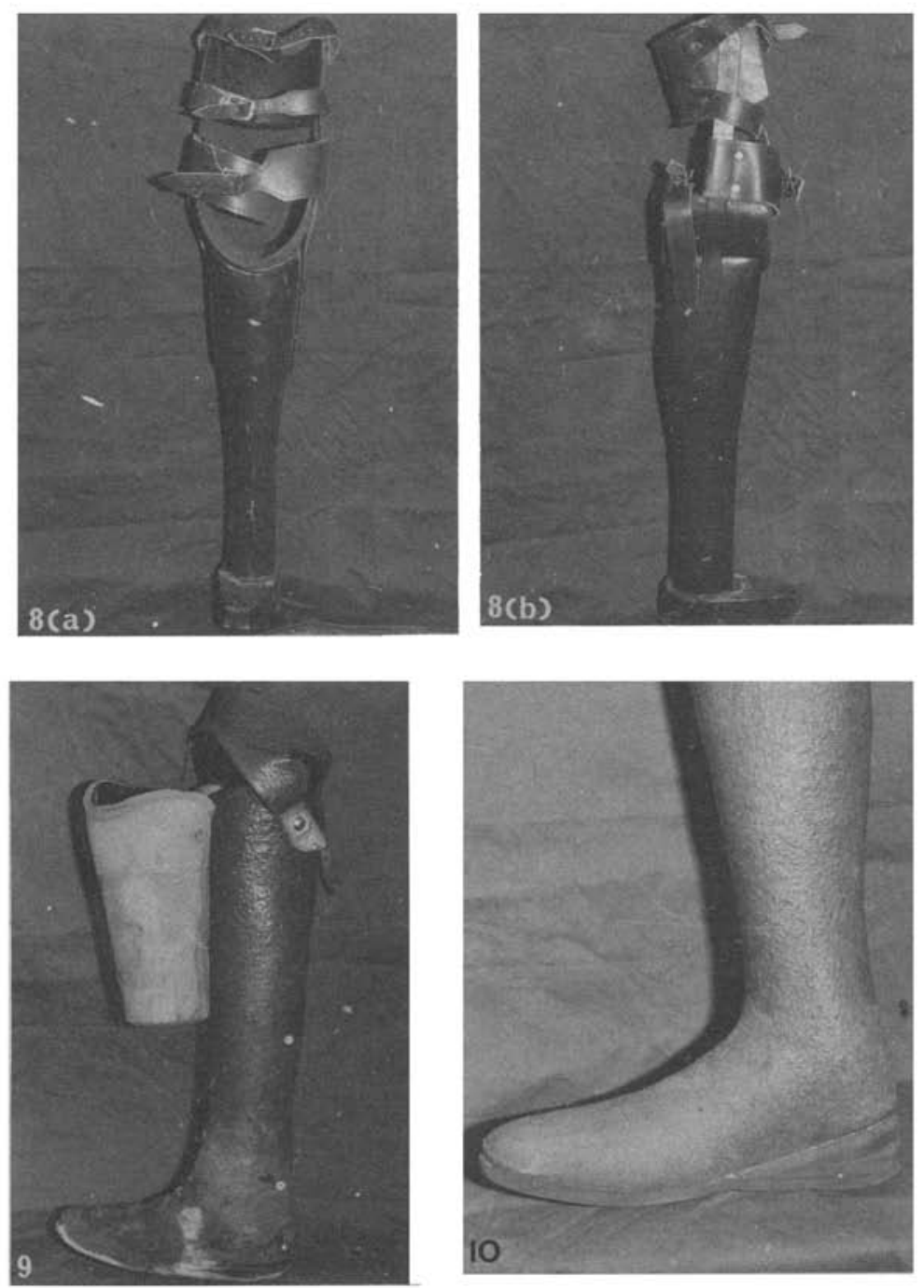

Fig. 8. The bent knee prosthesis gives a stiff-legged gait but is simple to make and very cheap. Patients find it quite satisfactory. One patient whose prosthesis was made with a one-inch soft iron rod for a leg piece wore it down $6 \mathrm{~cm}$ in 2 years. He came back only because his limb was too short.

Fig. 9. The Phaltzgraff prosthesis pictured with its plastazote liner removed is mid-way in sophistication and cost between the bent knee prosthesis and the hard socket patellar tendon bearing prosthesis. Some special skills and materials are needed, but any competent shoemaker can learn the techniques in a week or two.

Fig. 10. Because with rough usage the standard $\mathrm{SACH}$ foot and rubber toe do not last long an integral resin foot is preferable. Ideally the rocker conformation should be more accentuated than the model pictured. 


\section{References}

Cochrane, R. G. and Davey, T. F. (1964). Leprosy in Theory and Practice. Bristol: John Wright and Sons.

Fritschi, E. P. (1971). Reconstrictive Surgery in Leprosy. Pristol: John Wright and Sons.

Hart, R. J., Williams, H. W. and Scott, F. R. (1969). A new approach to the problem of grossly deformed feet. Lepr. Rev. 40, 59.

Pfaltzgraff, R. E. (1963). A prosthesis for below knee amputees. Lepr. Rev. 34, 8.

Ross, W. F. (1963). Oji River Settlement: Report on the patella tendon below knee prosthesis project. Lepr. Rev. 34, 151.

Wollstein, L. V. (1972). Technical remedies for the severely deformed foot in leprosy. Lepr. Rev. 43, 106. 